\title{
The relative difficulty of reversal and dimensional shifting as a function of overlearning'
}

\author{
ALICE F. SCHADE AND M. E. BITTERMAN \\ $B R Y N$ MAWR COLLEGE
}

\begin{abstract}
Pigeons were trained in series of discriminative problems with stimuli differing both in color and shape, one dimension relevant and the other irrelevant in each problem. An ORE for shape appeared late in the experiment, but color-reversal was retarded by overtraining. Overtraining on shape retarded shift to color, but overtraining on color had no effect on shift to shape. Where reversal and shifting differed in difficulty, shifting was easier; the opposite relation was not produced by overtraining.
\end{abstract}

\section{Problem}

It follows from the Sutherland-Mackintosh theory of the overlearning-reversal effect (ORE) that dimensional shifting should be more difficult than reversal for overtrained animals, but supporting evidence is lacking. In an experiment by Mackintosh (1962), overtraining facilitated reversal and retarded shifting (as the theory requires), but the design did not permit a direct comparison of the difficulty of shifting and reversal. In a recent experiment by Tighe, Brown, \& Youngs (1965), reversal was more difficult than shifting in overtrained rats. We report here an analogous experiment with pigeons.

\section{Method}

In a 2 by 2 by 2 factorial design, eight subgroups of pigeons $(\mathrm{A}-\mathrm{H})$ were given an original problem and two successive transfer-problems, one a reversal and the other a dimensional shift, in counterbalanced order over subgroups (Table 1). Half the subgroups were trained first with shape relevant, the other half with color relevant. Half of the subgroups were trained to criterion on each problem, while half had 20:0 trials of overtraining.

Ss (24 experimentally naive White Carneaux pigeons at $85 \%$ of satiated weights) were trained in a picnic chest with a panel containing a grain-magazine and three pigeon-keys. After key-training with the white center key, the animals had two days of training in which the stimuli to be correct in the first problem were presented alone, half the time on each of the two side keys, and responses to them reinforced. In the experimental training, each trial began (after a 6-sec. intertrial interval in darkness) with projection on the two side keys either of red triangle vs green vertical stripes, or green triangle vs. red vertical stripes, with each pair appearing equally often and in each spatial arrangement. After each correct response, the stimuli were turned off and grain was presented in the illuminated magazine-aperture for $2.5 \mathrm{sec}$. After an incorrect response, there was a $6-\mathrm{sec}$. timeout in darkness, after which the correct stimulus
TABLE I

Mean Errors to Criterion on Each Problem

(OL, overlearning: $R$, reversal: $S$, dimensional shifting)

\begin{tabular}{|c|c|c|c|c|}
\hline bgroup & Training & Problem 1 & Problem 2 & Problem 3 \\
\hline A & Crit & Shape 38.3 & Shape-R 126.7 & 28.7 \\
\hline B & Crite & Shape 47.0 & -S 22.3 & 44.7 \\
\hline C & Crite & Color 3.0 & Color-R & Shape-S \\
\hline D & Criter & Color 0.3 & Shape-S 86.0 & Shape-R 192.7 \\
\hline $\mathrm{E}$ & OL & Shape 51.0 & Shape-R 166.7 & Color-S 43.7 \\
\hline $\mathrm{F}$ & $\mathrm{OL}$ & Shape 61.0 & Color-S 33.3 & Color-R \\
\hline G & $\mathrm{OL}$ & Color 0.7 & Color- $R$ & Shape-S \\
\hline I & $\mathrm{OL}$ & Color & Shape-S & Shape-R 215.7 \\
\hline
\end{tabular}

alone was presented and the animal was reinforced for response to it. There were 40 trials per day to the criterion of no more than six errors on a given day with no more than three in the last 20 trials. All of the events of the experiment were programmed automatically.

\section{Results}

Table 1 presents the mean number of errors to criterion for each subgroup in each problem. Analyses were performed separately for each stimulus-dimension because color proved to be much easier than shape, and there was evidence from experiments on chicks that different effects might appear in dimensions of differing difficulty.

Overlearning and reversal. The ORE did not appear in the main experiment. A 2 by 2 analysis for shape based on cells A-2 (that is, Problem 2 for subgroup A), E-2, D-3, and H-3 of Table 1 showed no effect either of overlearning $(\mathrm{F}<1)$ or of previous training with color $(F=3.29, \mathrm{df}=1 / 8, \mathrm{p}>.05)$, and no interaction $(\mathrm{F}<1)$ 。A like analysis for color based on cells B-3, C-2, F-3, and G-2 showed that overlearning significantly retarded reversal $(F=11.15, \mathrm{df}=1 / 8, \mathrm{p}<.05)$ and that previous training with shape retarded reversal $(F=27.69, \mathrm{df}=1 / 8$, $\mathrm{p}<.01)$; the interaction was significant $(\mathrm{F}=6.66$, $\mathrm{df}=1 / 8, \mathrm{p}<.05)$. Previous experiments with chicks (Brookshire, Warren, \& Ball, 1961; Mackintosh, 1965) also have shown that overlearning on a visual dimension (brightness) may hinder reversal. In rats, hindrance of reversal by overlearning has not been found in visual dimensions.

Mackintosh's report (1965) of an ORE for shape in chicks led us to look beyond the main experiment for a like effect in pigeons. Subgroups $\mathrm{D}$ and $\mathrm{H}$ each were given one additional shape-reversal, subgroups $\mathrm{C}$ and $\mathrm{G}$ two additional shape-reversals. The first step in the treatment of the data was a 2 by 2 analysis of variance for cells $\mathrm{D}-2, \mathrm{C}-3, \mathrm{H}-2$, and $\mathrm{G}-3$, which showed no 


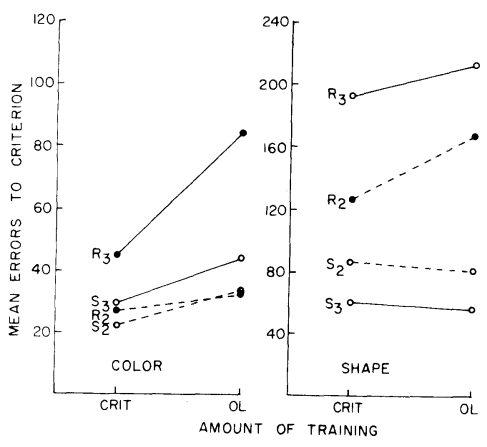

Fig. 1. Mean errors to criterion in reversals and dimensional shifts after training to criterion (crit) and after overlearning (OL) for each dimension. ( $R$, reversal $s$, dimensional shift $t^{\circ}$ the number with each $\mathbf{R}$ or $\mathbf{S}$ is the number of the problem.)

effect of overlearning on ease of shifting from color to shape $(F<1)$, no effect of previous color-reversal $(F<1)$, and no interaction $(F<1)$. Accordingly, the data for subgroups $C$ and $D$, and for subgroups $G$ and $H$, were pooled to permit a repeated-measures analysis of the effect of overlearning in the two post-shift shape-reversals. The mean errors for the first and second reversals were 222.4 and 274.6 for the criterioncondition, 194.8 and 138.6 for the overtraining condition. The analysis yielded a significant ORE ( $F$ for Conditions $=5.62, \mathrm{df}=1 / 8, \mathrm{p}<.05)$ and a significant Conditions by Reversals interaction $(F=13.24$, $d f=1 / 8, p<.01)$, although the effect of Reversals was not significant $(F<1)$. Orthogonal comparison indicated that the second of the two reversals was the one primarily responsible for the significant effect of Conditions ( $F$ for the first reversal $=1.72, \mathrm{df}=1 / 8, \mathrm{p}>.05)$. A marked crossover was evident in the learning curves for the second reversal; the overtrained group made more errors at first, but improved more rapidly, while the performance of the criterion group remained longer at the chance level. The curves for the first reversal did not differ appreciably from each other.

Overlearning and dimensional shifting. The effect of overtraining on shifting, like its effect on reversal, varied with dimension. The shift to form (cells D-2, $\mathrm{C}-3, \mathrm{H}-2$, and $\mathrm{G}-3$ ) was unaffected by overtraining on color; the results of this 2 by 2 analysis are given in the preceding paragraph. By contrast, the shift to color (cells A-3, B-2, E-3, and F-2) was significantly retarded by overtraining on shape $(F=8.44$, $\mathrm{df}=1 / 8$, $\mathrm{p}<.05)$. There was no effect of previous shape-reversal $(\mathrm{F}=3.46, \mathrm{df}=1 / 8, \mathrm{p}>.05)$, and no interaction $(\mathrm{F}<1)$.

The relative difficulty of reversal and dimensional shifting. The relative difficulty of reversal and dimensional shifting as a function of amount of training is shown in Fig. 1. Reversal tended to be more difficult than shift; the difference tended to increase with overlearning, to be greater for Problem 3 than for Problem 2, and to be greater for shape than for color. For Problem 2, 2 by 2 analyses for shape and for color gave no significant effect either of type of change or of overlearning, and no significant interaction. For Problem 3, reversal was significantly more difficult than shift in both dimensions ( $F$ for shape $=28.74$, $\mathrm{df}=1 / 8, \mathrm{p}<.01 ; \mathrm{F}$ for color $=17.26, \mathrm{df}=1 / 8, \mathrm{p}<.01)$; neither the effect of overlearning nor the interaction was significant for shape $(F<1)$, but the retarding effect of overlearning was significant for color $(\mathrm{F}=16.04, \mathrm{df}=1 / 8, \mathrm{p}<.01)$ 。

\section{Diseussion}

The basic Sutherland-Mackintosh notion is that discriminative learning involves two processes, dimensional (or "analyzer") selection and response-attachment. The ORE is explained on the assumption that overtraining strengthens analyzer-selection more than it strengthens response-attachment, making it possible for the animal to reverse while continuing to respond in terms of the relevant dimension. To the extent that overtraining strengthens analyzer-selection, it must be expected to retard shifting.

Some of the present results fit the theory. On the assumption that the animal comes to the situation with a relatively strong set for color, overtraining on color contributes little to the set and therefore does not retard the shift to shape but it retards reversal because it strengthens response-attachment. The fact that overtraining on shape retards shift to color follows from the assumption that the initial set for shape is relatively weak. By the same token, overtraining on shape should facilitate reversal, but there was no ORE in the main experiment. The ORE did appear later, but the theory is a long way from being able to specify the conditions for its appearance.

Our results on the relative difficulty of reversal and dimensional shifting, like those of Tighe, Brown, \& Youngs (1965), stand in clear contradiction to the theory. Mackintosh may conclude that not enough overtraining was given, but in our opinion it does not even follow clearly from the theory, as presently formulated (Mackintosh, in press), that shifting will be easier than reversal when training has been carried only to criterion. Compare a group of animals trained on Dimension A and shifted to Dimension B with a group trained on B and reversed. Both groups must substitute new response-attachments for old, but the shifted group must, in addition, find the new dimension.

\section{References}

Brookshire, K. H., Warren, J. M., \& Ball, G. G. Reversal and transfer learning following overtraining in rat and chicken. J. comp. physiol. Psychol., 1961, 54, 98-102.

Mackintosh, $\mathbf{N}$. J. The effects of overtraining on a reversal and a nonreversal shift. J. comp. physiol. Psychol., 1962, 55, 555-559.

Mackintosh, N. J. Overtraining and transfer within and between dimensions in the rat. Quart. J. exp. Psychol., 1964, 16, 250-255.

Mackintosh, N. J. Selective attention in animal discrimination learning. Psychol. Bull., in press

Tighe, T. J., Brown, P. L., \& Youngs, E. A. The effect of overtraining on the shift behavior of albino rats. Psychon. Sci., $1965,2,141-142$

Note

1. This research was supported by Contract Nonr 2829(01) with the Office of Naval Research 